\title{
Detection of hydrogen peroxide releasing from prostate cancer cell using a biosensor
}

\author{
Bruno P. Crulhas ${ }^{1} \cdot$ Naira P. Ramos $^{1} \cdot$ Gustavo R Castro $^{1} \cdot$ Valber A. Pedrosa $^{1}$
}

Received: 28 October 2015 /Revised: 7 March 2016/Accepted: 13 March 2016 /Published online: 23 March 2016

(C) Springer-Verlag Berlin Heidelberg 2016

\begin{abstract}
In this work, highly sensitive and selective hydrogel microstructures to detect hydrogen peroxide releasing from cancer cell based on electrochemical biosensors are proposed. Gold nanoparticles (AuNPs) were conjugated with horseradish peroxidase and were dispersed in the prepolymer solution of poly(ethylene glycol) diacrylate. The prepolymer solution was photolithographically patterned in alignment with an array of $\mathrm{Au}$ microelectrodes fabricated on glass. Performance of this biosensor was characterized by transmission electron microscopy, electrochemical impedance spectroscopy, and cyclic voltammetry. Under the optimal condition, the proposed biosensor can detect hydrogen peroxide $\left(\mathrm{H}_{2} \mathrm{O}_{2}\right)$ in a wide linear range from 2 to $100 \mu \mathrm{M}$ with a low detection limit of $0.01 \mu \mathrm{M}$. It can be also directly used to mark out extracellular $\mathrm{H}_{2} \mathrm{O}_{2}$ released from prostate cells. Furthermore, the reproducibility, stability, and selectivity of the biosensor are analogous with the previous report, so this methodology can be used in physiological and pathological detection of $\mathrm{H}_{2} \mathrm{O}_{2}$ in the future.
\end{abstract}

\section{Introduction}

Overall, inflammation is now recognized as a central feature of prevalent pathologies, such as atherosclerosis, inflammatory bowel disease, autoimmune disease, and cancer [1, 2]. Several research groups have focused on regulation of an inflammatory response to better understand reactive oxygen

Valber A. Pedrosa

vpedrosa@ibb.unesp.br

1 Universidade Estadual Paulista Julio de Mesquita Filho, Botucatu, SP, Brazil species (ROS) that arise through oxidative process. Hydrogen peroxide has been studied as ROS with a long known function during progressive inflammation step. As a by-product of oxidative metabolism in vivo, $\mathrm{H}_{2} \mathrm{O}_{2}$ is also known as the most stable reactive oxygen species implicated in cell proliferation, aging, death, and signal transduction [3, 4]. Also, it is involved in many regulatory cellular events including the activation of transcription factors, cell proliferation, and apoptosis [5]. In addition, $\mathrm{H}_{2} \mathrm{O}_{2}$ produced from the mitochondrial electron transport chain has been shown to play a role in hematopoietic cell differentiation and cell division in flies [6], and is capable of modulating a number of principal signaling cascades including ERK, JNK, p38, MAPK, and PI3K/Akt [7, 8]. As a result, $\mathrm{H}_{2} \mathrm{O}_{2}$ is an important indicator of inflammation and may serve as a diagnostic marker of the immune system.

Over the past decades, numerous researchers have worked on the development of integration of biological and sensing components that can be used in vitro [9-11]. Much effort is devoted to the immobilization of the different enzymes using different materials that can enhance sensor sensitivity and specificity $[12,13]$. Recently, electrodes modified with nanostructure have exhibited excellent enhancement of electronstransfer effects leading to unique optical, electronic, and catalytic properties $[14,15]$. The dimensions of these particles make them ideal candidates for the fabrication of functional nanostructures. Particularly, the combination of nanoparticle metals with hydrogel matrixes have attracted substantial research efforts directed to the development of the sensing materials that make them potential candidate materials to play the catalytic role in fabrication of a biosensing system $[16,17]$. Gold nanoparticle is one of the most studied nanomaterial that has excellent conductivity and catalytic properties, which makes it suitable for acting as "electronic wires" to enhance the electron transfer between redox centers in proteins and electrode surfaces, and as catalyst to increase electrochemical 
reactions. Due to its large specific surface area and high surface free energy, gold nanoparticles can adsorb biomolecules strongly and play an important role in the immobilization of biomolecules in biosensor construction. Also, it has been shown that the properties of nanostructures can be enhanced by the conductive environment provided by the polymeric matrixes. In particular, the incorporation of gold nanoparticle in conductive polymers is of interest because of the strong electronic interactions between the nanoparticle and the polymeric matrixes [18]. Recently, different authors have published alternative ways to adjust properties of hydrogels with nanoparticles, permitting the tuning or creation of new properties of the composite relative to the individual components $[19,20]$. In all of these previous methods, the biological components are deposited onto the polymer which can decrease the electron transfer rate constants. This decrease can be attributed to the lack of alignment of bioelectrocatalyst with the electrode surface.

In this study, an easy method to detect hydrogen peroxide release from cancer cell using a micropatterned biosensor is constructed. The combined polymer/nanoparticle does not only strikingly improve the sensitivity of different substrate, but also provides good repeatability and reproducibility, thus, can be potentially exploited for future studies in vitro to monitor cell metabolite fluxes.

\section{Experimental section}

\section{Materials}

Poly(ethylene)glycol diacrylate (PEG-DA, MW 575), 2hydroxy-2-methyl-propiophenone (photoinitiator), $99.9 \%$ toluene, horseradish peroxidase (HRP) (EC 1.11.1.7, type VI-A), mercapto-carboxylic acid (MUA), ferrocene monocarboxylic acid (FcMA), hydrogen peroxide, N-hydroxysuccinimide (NHS), 1-ethyl-3-(3-dimethylaminopropyl) carbodiimide (EDC), 3-(trichlorosilyl) propyl methacrylate, gold(III)chloride, and sodium citrate dihydrate were purchased from Sigma (St Louis, MO). Phosphate buffer (PBS) $0.1 \mathrm{M}$ was used as an electrolyte for all electrochemistry experiments. Water used for preparation of aqueous solutions came from a Millipore Direct-Q water purification system (resistivity, $18 \mathrm{M} \Omega \mathrm{cm}^{-2}$ ). Stock solutions were prepared in Milli-Q water and stored at $4{ }^{\circ} \mathrm{C}$.

\section{Preparation of prostate cancer cells}

PC-3 human prostate cancer cell lines (ATCC ${ }^{\circledR}$ CRL-1435 ${ }^{\mathrm{TM}}$ ) is a well-known lineage type used in prostate cancer research. These cells are useful in investigating biochemical changes in advanced prostatic cancer cells. Cells were cultivated in $75 \mathrm{~cm}^{2}$ flask in Roswell Park Memorial Institute Media supplemented with fetal bovine serum, L-glutamine and streptomycin $(10 \mathrm{mg})$, and penicillin $(10,000 \mathrm{U})$. All reagents were purchased from Gibco ${ }^{\circledR}$ (Waltham, MA). Cells were cultivated until they reached at least $90 \%$ of confluency. Right after, cells were trypsinized by using trypsin-EDTA (Gibco ${ }^{\circledR}$, Waltham, MA). Cells viability was evaluated by Neubauer chamber method.

\section{Design of Au electrode arrays}

Electrode layout was made in AutoCAD and transformed into plastic transparencies by DGM design (Curitiba, Brazil). Fabrication of gold electrode arrays, were made at the Brazilian Nanotechnology National Laboratory (LNNanoCNPEM, Campinas/SP). Sputter-coated standard $(75 \mathrm{~mm} \times 25 \mathrm{~mm})$ glass slides were developed with $15 \mathrm{~nm}$ $\mathrm{Cr}$ adhesion layer and $100 \mathrm{~nm}$ Au layer. Electrodes were produced by photoresist lithography and wet etching. Etching of $\mathrm{Au} / \mathrm{chrome}$ layers in an array of eight working microelectrodes patterned on a glass slide. Each Au electrode was $300 \mu \mathrm{m}$ in diameter with $15 \mu \mathrm{m}$ wide leads and $1 \mathrm{~mm} \times 1 \mathrm{~mm}$ square contact pad (Fig. 1a).

\section{Establishment of gold nanoparticles HRP-carrying hydrogel microstructures on Au electrode arrays}

Gold nanoparticles were synthesized by standard wet chemical methods using sodium citrate as a reducing agent, and MUA-AuNPs were conjugated by ligand exchange between

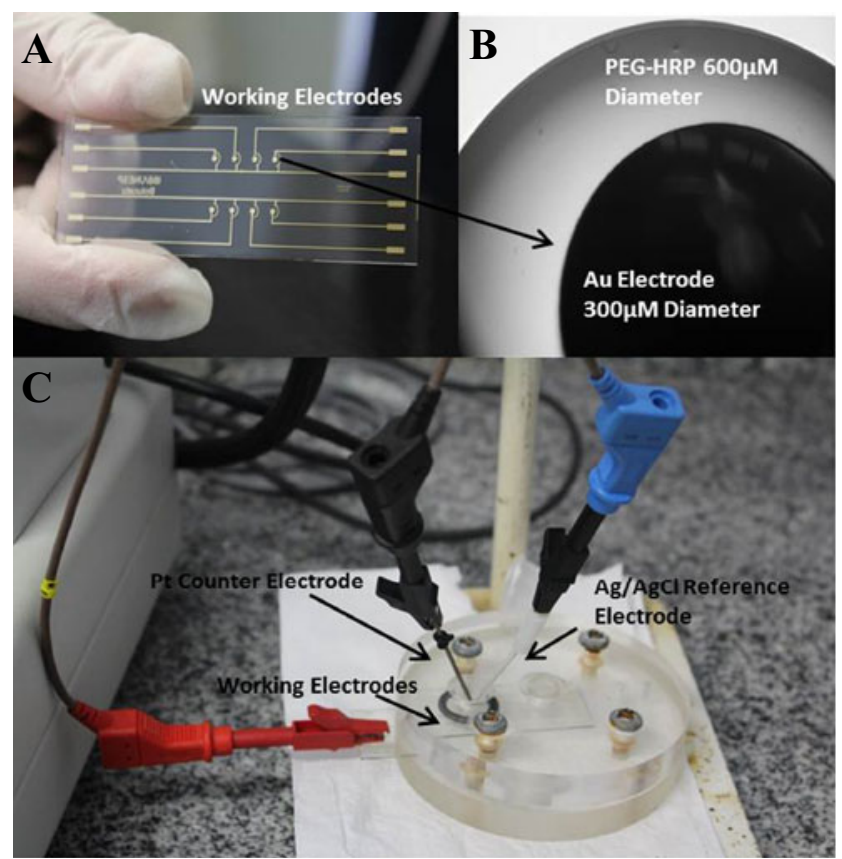

Fig. 1 a Overview of sensing chip containing eight micropatterned $\mathrm{Au}$ electrodes. b PEG-HRP polymerized on top of Au electrode. c Electrochemical experiments containing $\mathrm{Ag} / \mathrm{AgCl}$ as reference, $\mathrm{Pt}$ wire as counter, and patterned $\mathrm{Au}$ as working electrodes 
mercapto-carboxylic acid and citrate-stabilized gold nanoparticles (AuNPs), by previous reported papers [21]. The gold nanoparticle was analyzed by uv-vis spectrum. Briefly, $0.5 \mathrm{~mL}$ suspension of Au nanoparticle was gently added to $0.5 \mathrm{~mL}$ MUA solution (70\% of ethanol) and stirred for $4 \mathrm{~h}$. Subsequently, the mixture was centrifuged at $9000 \mathrm{rpm}$ for $15 \mathrm{~min}$ to remove excess alkanethiol and resuspended in phosphate buffer (10 mM, pH 6.5).

Attachment of enzyme horseradish peroxidase to MUA/AuNP was prepared using EDC/NHS conjugation. In summary, $1 \mathrm{~mL}$ MUA-AuNPs solution was incubated and stirred for $2 \mathrm{~h}$ with $100 \mathrm{mM}$ NHS and $200 \mathrm{mM}$ EDC solution and finally added $0.1 \mathrm{~mL}$ of HRP solution $(15 \mathrm{mg} / \mathrm{mL}$ in $10 \mathrm{mM}$ of PBS at pH 6.0) and left stirring overnight. Quality of AuNPs was verified by electro transfer microscopy (Fig. 2a, b).

Simultaneous with the HRP-AuNPs preparation, prepolymer solution containing PEG-DA and $2 \%(v / v)$ photoinitiator (2-hydroxy-2-methyl-propiophenone) was made and mixed with $0.1 \mathrm{~mL}$ of HRP-AuNPs by sonication for $1 \mathrm{~min}$ and then stirred overnight at $4{ }^{\circ} \mathrm{C}$. Prior to the immobilization of hydrogel, glass slides were silanized as following standard protocol. Briefly, glass slides were cleaned in "piranha" solution consisting of 3:1 ratio of $\mathrm{H}_{2} \mathrm{SO}_{4}$ and $\mathrm{H}_{2} \mathrm{O}_{2}$ for $30 \mathrm{~min}$, washed in Milli-Q water, and subsequently immersed in $2 \mathrm{mM}$ toluene solution of 3-(trichlorosilyl) propyl methacrylate (TPM) for $1 \mathrm{~h}$ to obtain a self-assembled silane monolayer then substrates were washed to remove excess of silane agent and placed in an oven for $3 \mathrm{~h}$ at $100{ }^{\circ} \mathrm{C}$ to crosslink the silane layer.

The PEG-based prepolymer solution was spin-coated at $800 \mathrm{rpm}$ for $4 \mathrm{~s}$ onto glass slides containing Au electrode patterns. A photomask was registered with an electrode pattern and then exposed to UV light at $65 \mathrm{~mW} / \mathrm{cm}^{2}$ for $10 \mathrm{~s}$ to convert liquid prepolymer into cross-linked hydrogel. Surfaces were developed in DI water for $3 \mathrm{~min}$ to remove the unpolymerized PEG precursor solution. Enzyme-AuNPs carrying hydrogel microstructures were made larger than $\mathrm{Au}$ electrodes; feature sizes were 600 and $300 \mathrm{~mm}$ in diameter for hydrogel elements and Au electrodes, respectively. This was done to ensure effective anchoring of the hydrogel structures to silanized glass substrates (Fig. 1b).

\section{Electrochemical detection of $\mathrm{H}_{2} \mathrm{O}_{2}$}

A potentiostat $\mu$ AutoLabIII (Metrohn, NL) was employed for the cyclic voltammetry (CV) experiments. The electrochemical cell consisted of an $\mathrm{Ag} / \mathrm{AgCl}(3 \mathrm{M} \mathrm{KCl})$ reference electrode, a platinum wire counter electrode placed, and Au working electrodes positioned inside the electrochemical cell (Fig. 1c); all experiments were done in quintuplicates.
Fig. 2 a Transmission electron microscopy (TEM) images of gold nanoparticle. b TEM images of HRP conjugated with AuNP. c TEM images of HRP/AuNPs dispersed into PEG-hydrogel matrix. d The UV-vis spectrum of AuNPs
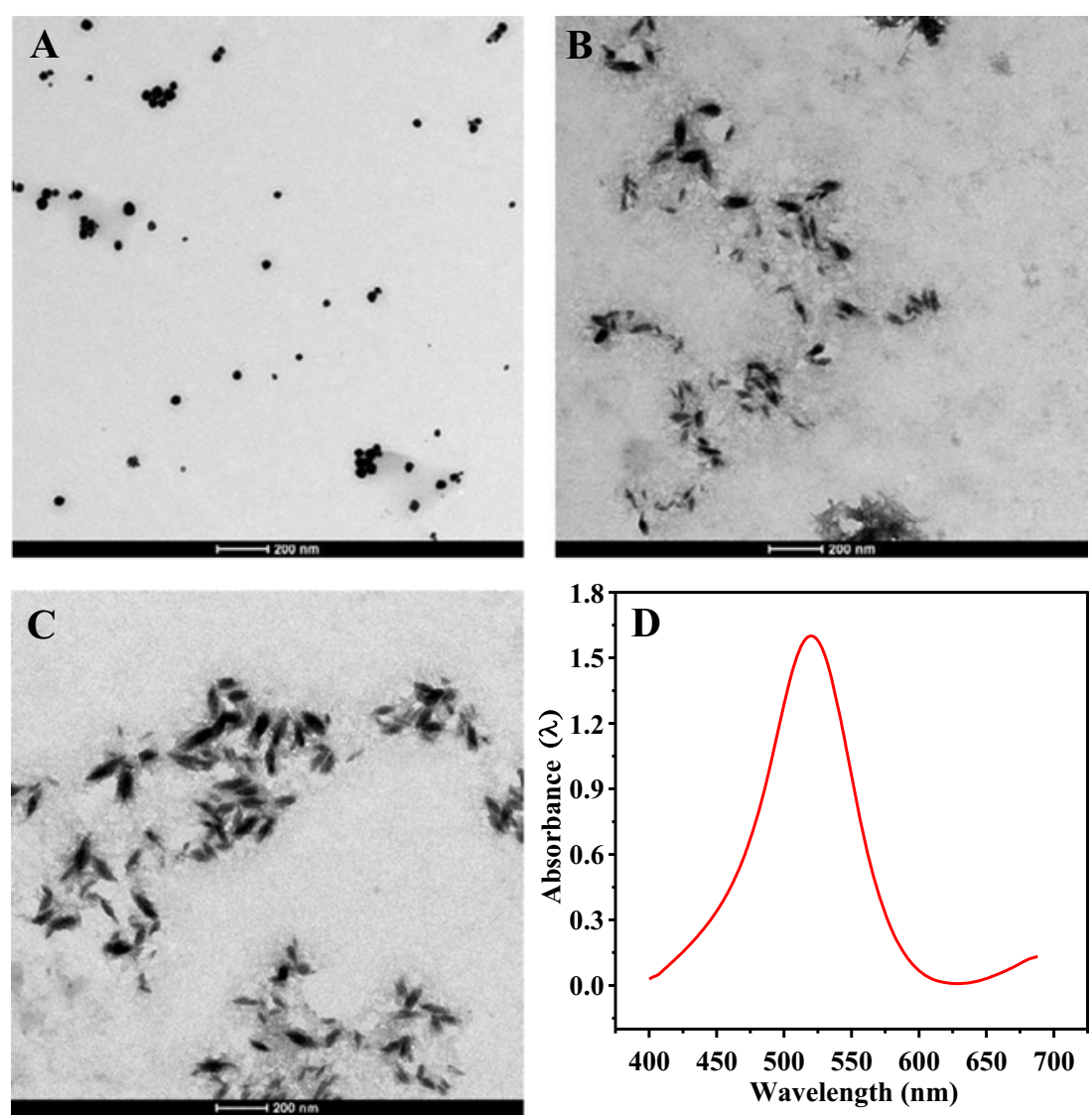
Cyclic voltammetry was used to detect $\mathrm{H}_{2} \mathrm{O}_{2}$ by PEGHRP-AuNPs electrodes. Briefly, several $\mathrm{H}_{2} \mathrm{O}_{2}$ concentrations were prepared in PBS and infused into the electrochemical cell containing enzyme-AuNPs-based electrodes and analyzed by cyclic voltammograms from 0.8 to $-0.8 \mathrm{~V}$ at the scan rate of $50 \mathrm{mV} / \mathrm{s}$. For validating the specificity, the biosensor was tested in the presence of interfering compounds $(10 \mathrm{mM}$ of ascorbic acid and $10 \mathrm{mM}$ of uric acid).

Calibration curve was constructed by plotting absolute value for reduction current at $-0.4 \mathrm{~V}$ versus $\mathrm{H}_{2} \mathrm{O}_{2}$ concentration when compared to control without hydrogen peroxide. Limit of detection (LOD) was calculated based on calibration curve using linear regression by the standard deviation of y-intercept ( $\mathrm{LOD}=3 \sigma / \mathrm{slope}$ ), and sensitivity was calculated using working electrode surface area.

To detect $\mathrm{H}_{2} \mathrm{O}_{2}$ production from prostate cancer cells (PC3), cells were incubated onto the surface of the electrode. PC3 cells are an aggressive type of prostate cancer, and association between prostatic cancer and oxidative stress has been well-recognized. There is considerable evidence suggesting oxidative stress contributes to the etiology and pathogenesis of the prostate cancer; therefore, small amount of hydrogen peroxide is naturally released by PC3 cells [22]. Briefly, prior to seeding of the cells, the surface was treated with $0.2 \mathrm{mg} / \mathrm{mL}$ of collagen (I) to promote cell attachment. Subsequently, PC3 cells were suspended in cell culture medium at a concentration of 106 cells $\mathrm{mL}^{-1}$ and incubated at $37{ }^{\circ} \mathrm{C}$ over the surface of the biochip for $1 \mathrm{~h}$. CV measurements were made every 20 min during the $2.5 \mathrm{~h}$.

\section{Results and discussion}

\section{Electrochemical characterization of enzyme-AuNPs biosensors}

HRP-AuNPs-PEG sensor was manufactured by polymerizing enzyme-hydrogel on top of micropatterned Au electrodes (Fig. 1b). HRP enzyme with AuNPs was conjugated and incorporated into hydrogel microstructures in order to increase sensitivity and stability of the biosensor and also optimize enzyme retention into hydrogel.

The morphology of modified AuNP was characterized by TEM. Figure 2 a shows the well-dispersed AuNP with a size of about $22 \mathrm{~nm}$ in diameter, and also by Uv-vis spectrum of AuNPs particles with a peak at $520 \mathrm{~nm}$ (Fig. 2d). The microstructural investigation of AuNPs-HRP was carried out using TEM to reveal size, shape, and distribution of the particles. From the micrographs, it is observed that an aggregation step and the size of particles increased due to the presence of the enzyme (Fig. 2b). The size of spherical thiolated gold nanoparticles conjugated with HRP is found to be varying around 30 to $50 \mathrm{~nm}$. Figure $2 \mathrm{c}$ shows the dispersion of AuNPs into PEG matrix being similar to dispersion of AuNPs in buffer.

To characterize the voltammetric behavior of the biosensor, a set of experiments was conducted using cyclic voltammetry in the presence of $0.5 \mathrm{mM} \mathrm{FcMA}$ in $10 \mathrm{mM}$ PBS buffer at scan rates varying from 20 to $250 \mathrm{mV} \mathrm{s}^{-1}$. The results obtained show that with increased scan rate, the redox peak current also increased gradually (Fig. 3a). The correlation of redox peak currents with scan rate is shown in Fig. 3c. Peak currents were
Fig. 3 a Cyclic voltammograms of HRP-AuNP-PEG Au electrode at different scan rates $(a-f 20,30$, $60,100,200$, and $250 \mathrm{mV} / \mathrm{s})$ in the presence of $0.5 \mathrm{mM} \mathrm{FcMA}$ in 10 mM PBS buffer (pH 6.5). b Peak-to-peak separation as a function of the potential scan rate. c Plot of redox peaks current versus square root of scan rate, cathodic peak (red circle), and anodic peak (black square) HRPAuNP-PEG. d Impedance spectroscopy PEG-Au electrodes. Nyquist plots for PEG/Au electrodes containing HRP-PEG (black square) and (red circle) HRP-AuNP-PEG frequency intervals were from $0.1 \mathrm{~Hz}$ to $1 \mathrm{mHz}$
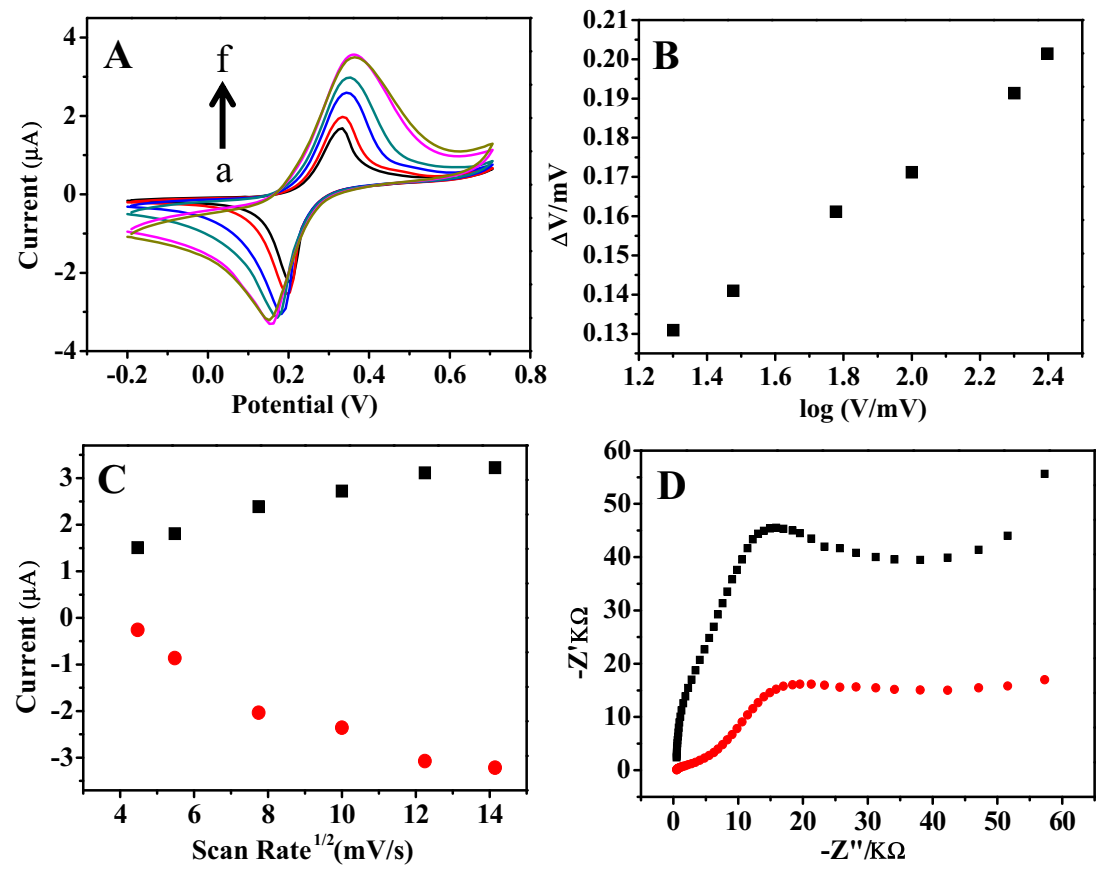
proportional to square root of scan rate $\left(v^{1 / 2}\right)$, which indicates a diffusion controlled process. To better understand, the reaction mechanism was analyzed by peak potential versus scan rate. Separation of peak-to-peak $(\Delta E p)$ remains nearly constant up to $60 \mathrm{mV}$, which suggests an electrochemical process reversibly confined surface (Fig. 3b).

In addition, electrochemical impedance spectroscopy (EIS) experiments were used to evaluate charge transfer resistance. Figure $3 \mathrm{~d}$ displays typical Nyquist plots of impedance of various electrodes recorded in a frequency range of $0.1 \mathrm{~Hz}-$ $100.0 \mathrm{kHz}$ in PBS $(0.05 \mathrm{M}, \mathrm{pH} 7.2)$ containing $0.5 \mathrm{mM}$ FcMA in $10 \mathrm{mM}$ of PBS. Electron-transfer kinetics such as charge transfer resistance $\left(R_{\mathrm{ct}}\right)$, solution resistance $\left(R_{\mathrm{s}}\right)$, double layer capacitance $\left(C_{\mathrm{d}}\right)$, and a mass transfer element $W$ (Warburg impedance) could be extracted by EIS data fitting. The electron-transfer resistance $\left(R_{\mathrm{et}}\right.$, the diameter of semicircle) of redox probe measuring ferrocene reactivity on gold microelectrode (red line) and after enzyme attached (black line) were 30 and $45 \mathrm{~K} \Omega$, respectively (Fig. 3d). This means that the resistance increased with the enzyme deposited on top of the microelectrode. [23].
$\mathrm{H}_{2} \mathrm{O}_{2}$ is an electroactive compound, and it was a verified reduction process in absence and presence of HRP conjugated with AuNPs and PEG hydrogel. CVs of step by step preparation of electrode in the presence of $\mathrm{H}_{2} \mathrm{O}_{2}$ was done to ensure that the incorporation of redox enzyme conjugated with AuNPs in hydrogel matrix increased current response in both positive and negative potential ranges when compared to response for only hydrogel or AuNP-Hydrogel (Fig. 4a). Therefore, increase in reduction current was obtained by adding $\mathrm{H}_{2} \mathrm{O}_{2}$ into electrochemical cell containing microelectrodes, which indicates reduction and diffusion of $\mathrm{H}_{2} \mathrm{O}_{2}$ to hydrogel. In contrast, electrodes made with only pure PEG did not show changes in current when challenged with $\mathrm{H}_{2} \mathrm{O}_{2}$ (Fig. 4a).

Thus, it validates that HRP enhances with the reduction of $\mathrm{H}_{2} \mathrm{O}_{2}$. Calibration curve of enzyme-AuNPs sensor was performed by spiking known concentrations of $\mathrm{H}_{2} \mathrm{O}_{2}$ into the device containing HRP-AuNPs-PEG electrodes and used $\mathrm{CV}$ to monitoring reduction current in range of 0.8 to $-0.8 \mathrm{~V}$. Injected with different concentrations of $\mathrm{H}_{2} \mathrm{O}_{2}$ diffuses it into hydrogel matrix and reacts with HRP entrapped inside
Fig. 4 a CV plots of PEG (blue line), AuNP-PEG(red line), and HRP-AuNP-PEG(black line) polymerized onto Au electrodes in the potential range of 0.7 to $-0.7 \mathrm{~V}$ at the scan rate of $50 \mathrm{mV} / \mathrm{s}$ and in the presence of $5 \mathrm{mg} / \mathrm{mL}$ of $\mathrm{H}_{2} \mathrm{O}_{2}$. b CV plots of the PEG$\mathrm{HRP}$ electrode as a function of $\mathrm{H}_{2} \mathrm{O}_{2}(a-f 1,5,10,20,50$, and $100 \mathrm{mg} / \mathrm{mL})$. The reductive current increases with increasing concentration of $\mathrm{H}_{2} \mathrm{O}_{2}$. This indicates enhanced enzymatic reaction between $\mathrm{HRP}$ and $\mathrm{H}_{2} \mathrm{O}_{2}$. c Calibration plot obtained for HRP-AuNP-PEG electrode showing absolute value of the reduction current as a function of different $\mathrm{H}_{2} \mathrm{O}_{2}$ concentrations. d CV plots of HRP-AuNP-PEG. e Reproducibility plot of HRPAuNP-PEG biosensor
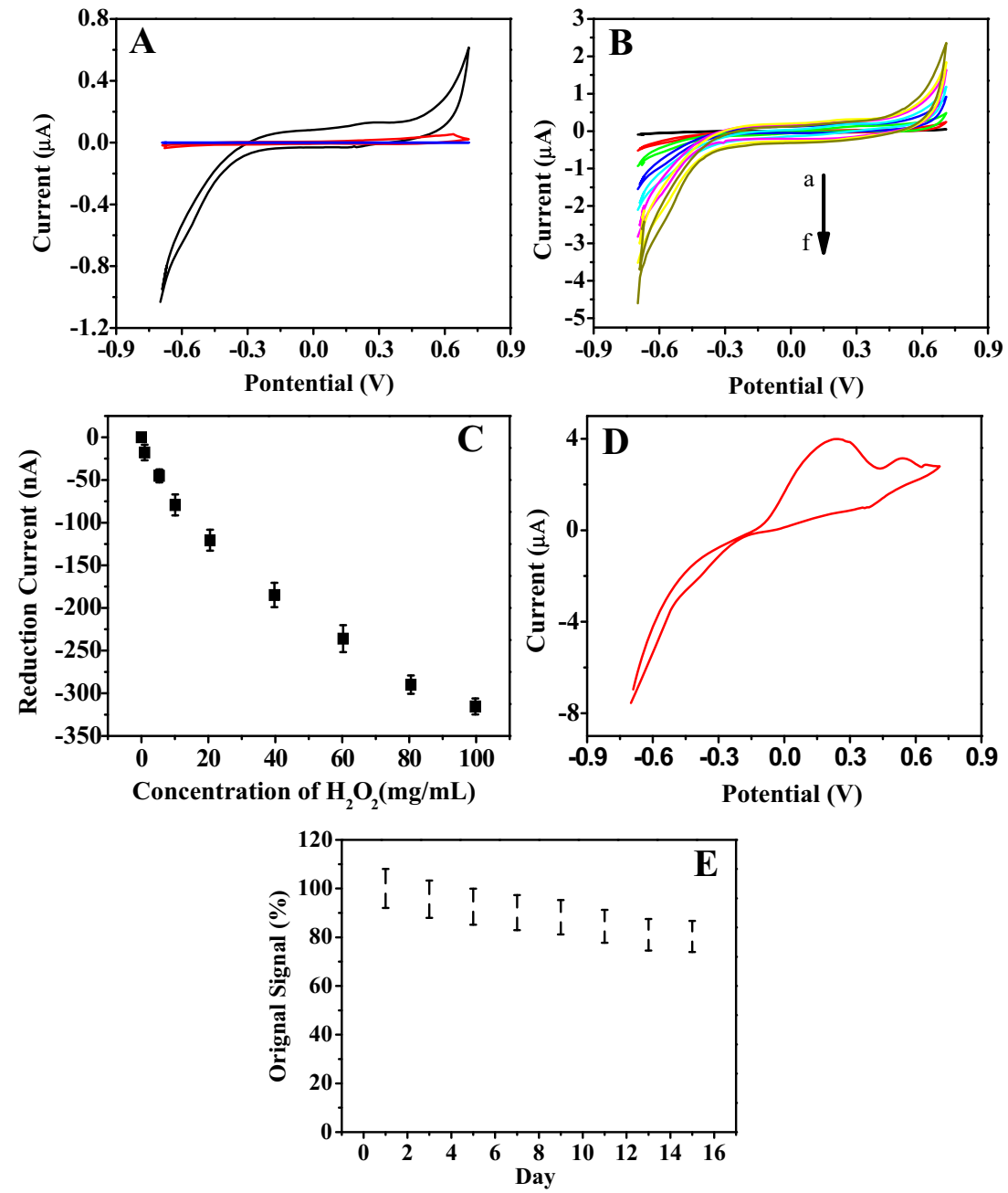
the hydrogel (Fig. 4b). Figure 4c shows calibration plot (reduction current versus $\mathrm{H}_{2} \mathrm{O}_{2}$ concentration at $-0.4 \mathrm{~V}$ ) for detection of $\mathrm{H}_{2} \mathrm{O}_{2}$. The low operating potential $(-0.4 \mathrm{~V})$ was used because it avoids interference due to other competitive species such as ascorbic acid and uric acid [24].

In order to avoid unspecific interaction with small molecules generally found in physiological fluids, like ascorbic acid and uric acid, we verified the effects of these interfering compounds into our biosensor by CVs and it was able to detect $\mathrm{H}_{2} \mathrm{O}_{2}$ in the presence of high concentrations of ascorbic acid and uric acid because reduction signal of $\mathrm{H}_{2} \mathrm{O}_{2}$ was evaluated at $-0.4 \mathrm{~V}$ and the peak of ascorbic acid and uric acid appeared at 0.2 and $0.6 \mathrm{~V}$, respectively Fig. $4 \mathrm{~d}$.

The lowest concentration of $\mathrm{H}_{2} \mathrm{O}_{2}$ that could be detected by each sensing electrode of area $0.0708 \mathrm{~mm}^{2}$ was found to be $0.01 \mu \mathrm{M}\left(R^{2}=0991\right)$. Sensitivity of the sensor was calculated to be $18.5 \mathrm{nA} \mu \mathrm{M} / \mathrm{mm}^{2}$. Stability of enzyme - AuNPs-hydrogel electrode was verified at a regular interval of 1 week by infusing a $20-\mu \mathrm{M}$ concentration of $\mathrm{H}_{2} \mathrm{O}_{2}$ in the electrochemical cell with HRP-AuNPs-PEG sensor.

The HRP-PEG-AuNPs biosensors were highly reproducible with a standard deviation of $8 \%$ in hydrogen peroxide detection. The working electrode was stable after 2 weeks of testing. Coupling of AuNPs with PEG hydrogels provides an excellent matrix for electrochemical detection due to inclusion of redox sites into the hydrogel being a reliable tool for use in clinical diagnostics.

\section{Electrochemical detection of $\mathrm{H}_{2} \mathrm{O}_{2}$ released by prostate cancer cells}

To conduct biological experiments with prostate cancer, PC3 cells were seeded onto collagen (I)-coated surfaces containing enzyme-AuNPs electrodes (Fig. 5a, b). The device containing cells and electrode were kept in a tissue culture incubator at $37{ }^{\circ} \mathrm{C}$ for $24 \mathrm{~h}$. Prostate cancer cells did not attach on top of electrodes due to non-fouling properties of PEG. An estimated $1,000,000,00$ cells were cultured inside the electrochemical cell during sensing experiment.

Release of $\mathrm{H}_{2} \mathrm{O}_{2}$ was detected with $\mathrm{CV}$ by diffusion of $\mathrm{H}_{2} \mathrm{O}_{2}$ inside hydrogel, and measurements were made every $20 \mathrm{~min}$ in a span of $2.5 \mathrm{~h}$. Increase in reduction current of $\mathrm{H}_{2} \mathrm{O}_{2}$ was observed right after first measurement, showing constant production of $\mathrm{H}_{2} \mathrm{O}_{2}$ from PC3 cells (Fig. 5c). Reduction current did not saturate after $2.5 \mathrm{~h}$, proving the feasibility and stability of the sensor which was not compromised by non-specific proteins and by-product released by PC3 cells. Figure 5c represents reduction current response to PC3 cells to $\mathrm{H}_{2} \mathrm{O}_{2}$. Further, a control experiment was done using the same methodology of modified hydrogel patterned on electrodes without HRP and was designed to test whether detection of cellular response requires the presence of peroxide-specific enzyme HRP. In the absence of HRP, no

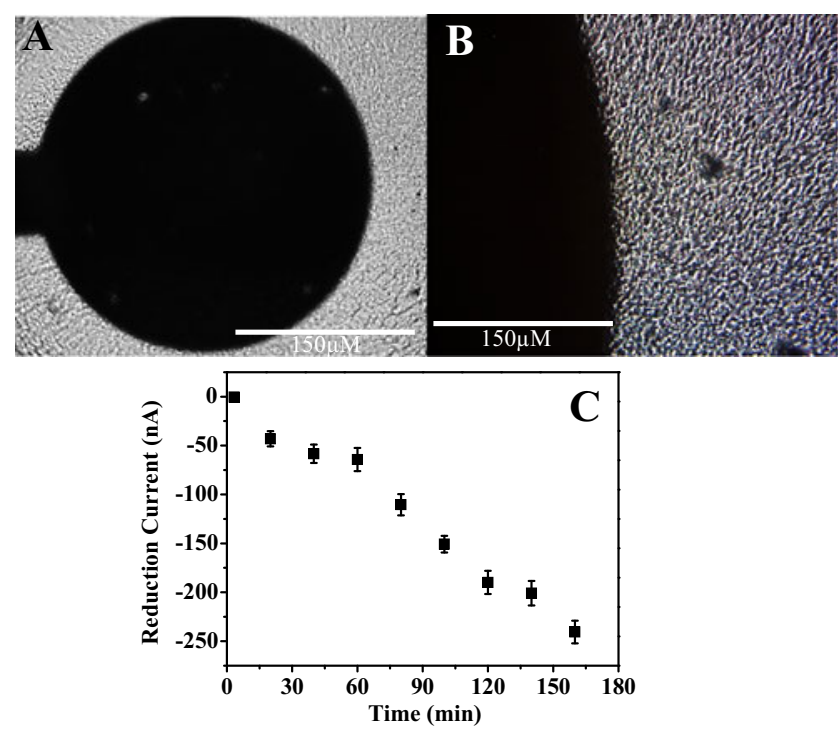

Fig. 5 Sensor surface. a Microscopy image $10 \times$ of PC3 cells seeding onto collagen-modified silane region around HRP-AuNP-PEG electrode. b Microscopy image $40 \times$ of PC 3 cells seeding onto collagen-modified silane region around HRP-AuNP-PEG electrode. $\mathbf{c}$ Plot showing absolute value of the reduction current as a function of $\mathrm{H}_{2} \mathrm{O}_{2}$ released by cells

reductive current was detected. This control experiment further validated that the analyte produced by cells and detected at the sensing electrodes was indeed $\mathrm{H}_{2} \mathrm{O}_{2}$.

The biosensor is the first one to use enzymes coupled with AuNPs and hydrogel to detect $\mathrm{H}_{2} \mathrm{O}_{2}$ released by cancer cells; the majority of this type of platform is used to detect ROS released by immune cells [24-27]. Similar experiments were made by Revzin et al. [28] and when compared with similar sensors found in literature, the sensor used in this work achieved better results from sensitivity, stability, and limit of detection (Table 1).

\section{Conclusion}

The study describes the use of enzyme-AuNPs-PEG electrodes to enable detection of $\mathrm{H}_{2} \mathrm{O}_{2}$ from cancer cells by a photolithography process. The biosensor had a detection limit of $0.01 \mu \mathrm{M} \mathrm{H}_{2} \mathrm{O}_{2}$ with linear range extending to $100 \mu \mathrm{M}$. A microsystem utilizing enzyme-AuNPs-based electrodes was

Table 1 Comparison of analytical performance of $\mathrm{H}_{2} \mathrm{O}_{2}$ biosensor

\begin{tabular}{lll}
\hline $\mathrm{H}_{2} \mathrm{O}_{2}$ biosensor & Detection limit $(\mathrm{mM})$ & Reference \\
\hline HRP-AuNP-PEG & 0.001 & This work \\
HRP-AuNP & 0.003 & {$[29]$} \\
HRP-ferrocene & 2.32 & {$[30]$} \\
HAP- $\alpha$-zirconium phosphate/GC & 12 & {$[31]$} \\
HRP-nano-Au-carbon ceramic & 61 & {$[32]$} \\
HRP-DNA/GC & 25 & {$[33]$} \\
\hline
\end{tabular}


used to detect prostate cancer cell production of $\mathrm{H}_{2} \mathrm{O}_{2}$ that ranged from $0.07 \mu \mathrm{M}$ at $20 \mathrm{~min}$ to $2.36 \mu \mathrm{M}$ after $2.5 \mathrm{~h}$. Due to conjugation of enzyme with AuNPs inside the hydrogel, the biosensor achieved excellent stability and feasibility due to PEG non-fouling properties. Moreover, it can be also used to efficiently monitor the extracellular $\mathrm{H}_{2} \mathrm{O}_{2}$ released from human prostate cancer cells. Therefore, this biosensor might be useful for the further physiological and pathological applications, like cancer and inflammatory process that releases hydrogen peroxide.

Acknowledgments We gratefully acknowledge partial support by grants from the FAPESP (2014/05653-5, 2012/15666-1), CNPq, and CAPES.

\section{References}

1. Coussens LM, Werb Z (2002) Inflammation and cancer. Nature 420:860-867

2. Serhan CN, Savill J (2005) Resolution of inflammation: the beginning programs the end. Nat Immunol 6:1191-1197

3. Henzler T, Steudle E (2000) Transport and metabolic degradation of hydrogen peroxide in Chara corallina: model calculations and measurements with the pressure probe suggest transport of $\mathrm{H}_{2} \mathrm{O}_{2}$ across water channels. J Exp Bot 51:2053-2066

4. Lindahl T (1993) Instability and decay of the primary structure of DNA. Nature 362:709-715

5. Rojkind M, Domínguez-Rosales JA, Nieto N, Greenwel G (2002) Role of hydrogen peroxide and oxidative stress in healing responses. Cell Mol Life Sci 59:1872-1891

6. Bedard K, Krause KH (2007) The NOX family of ROS-generating NADPH oxidases: physiology and pathophysiology. Physiol Rev $87: 245-313$

7. Hensley K, Robinson KA, Gabbita SP, Salsman S, Floyd RA (2000) Reactive oxygen species, cell signaling, and cell injury. Free Radic Biol Med 28:1456-1462

8. Gabbita SP, Robinson KA, Stewart CA, Floyd RA, Hensley K (2000) Redox regulatory mechanisms of cellular signal transduction. Arch Biochem Biophys 376:1-13

9. Liu Y, Kwa T, Revzin A (2012) Simultaneous detection of cellsecreted TNF-a and IFN-g using micropatterned aptamermodified electrodes. Biomaterials 33(30):7347-7355

10. Yan J, Pedrosa VA, Simonian AL, Revzin A (2010) Immobilizing enzymes onto electrode arrays by hydrogel photolithography to fabricate multi-analyte electrochemical biosensors. ACS Appl Mater Interfaces 2:748-755

11. Yan J, Pedrosa VA, Enomoto J, Simonian A, Revzin A (2011) Electrochemical biosensors for on-chip detection of oxidative stress. Biomicrofluidics 5(3):32008-32011

12. Pita M, Kramer M, Zhou J, Poghossian A, Schoning MJ, Fernandez VM, Katz E (2008) Optoelectronic properties of nanostructured ensembles controlled by biomolecular logic systems. ACS Nano 2:2160-2166

13. Tuleuova N, Jones CN, Yan J, Ramanculov E, Yokobayashi Y, Revzin A (2010) Development of an aptamer beacon for detection of interferon-gamma. Anaytical Chemistry 82:1851-1857

14. Pedrosa VA, Paliwal S, Balasubramanian S, Nepal D, Davis V, Wild J, Ramanculov E, Simonian A (2010) Enhanced stability of enzyme organophosphate hydrolase interfaced on the carbon nanotubes. Colloids and Surfaces B 77:69-74
15. Nemzer LR, Schwartz A, Epstein AJ (2010) Enzyme entrapment in reprecipitated polyaniline nano- and microparticles. Macromolecules 43:4324-4330

16. Jagur-Grodzinski J (2010) Polymeric gels and hydrogels for biomedical and pharmaceutical applications. Polymers for Advance Technol 21:27-47

17. Cong H, Revzin A, Pan T (2009) Non-adhesive PEG hydrogel nanostructures for self-assembly of highly ordered colloids. Nanotechnology 20(7):75307

18. Li J, Seok S, Chu B, Dogan F, Zhang Q, Wang Q (2009) Nanocomposites of ferroelectric polymers with $\mathrm{TiO}_{2}$ nanoparticles exhibiting significantly enhanced electrical energy density. Adv Mater 21:217-221

19. Zhai D, Liu B, Shi Y, Pan L, Wang Y, Li W, Zhang R, Yu G (2013) Highly sensitive glucose sensor based on Pt nanoparticle/ polyaniline hydrogel heterostructures. ACS Nano 7(4):3540-3546

20. Zhang R, Xu S, Luo J, Liu X (2015) Molecularly imprinted photosensitive polyglutamic acid nanoparticles for electrochemical sensing of hemoglobin. Microchim Acta 182:175-183

21. Pedrosa VA, Yan J, Simonian AL, Revzin A (2011) Micropatterned nanocomposite hydrogels for biosensing applications. Electroanalysis 23:1142-1149

22. Kumar B, Koul S, Khandrika L, Randall B, RB M, HK K (2008) Oxidative stress is inherent in prostate cancer cells and is required for aggressive phenotype. Cancer Res 68(6):1777-1785

23. Katz E, Willner I (2003) Probing biomolecular interactions at conductive and semiconductive surfaces by impedance spectroscopy: routes to impedimetric immunosensors, DNA-sensors, and enzyme biosensors. Electroanalysis 15(11):913-947

24. Heller I, Smaal WT, Lemay SG, Dekker C (2009) Probing macrophage activity with carbon-nanotube sensors. Small 22:2528-2532

25. Amatore C, Arbault S, Chen Y, Crozatier C, Tapsoba I (2007) Electrochemical detection in a microfluidic device of oxidative stress generated by macrophage cells. Lab Chip 7:233-238

26. Cheah LT, Dou YH, Seymour AML, Dyer CE, Haswell SJ, Wadhawanc JD, Greenman J (2010) Microfluidic perfusion system for maintaining viable heart tissue with real-time electrochemical monitoring of reactive oxygen species. Lab Chip 10:2720-2726

27. Li C, Zhang H, Wu P, Gong Z, Xu G, Cai C (2011) Electrochemical detection of extracellular hydrogen peroxide released from RAW 264.7 murine macrophage cells based on horseradish peroxidasehydroxyapatite nanohybrids. Analust 136:1116-1123

28. Matharu Z, Enomoto J, Revzin A (2013) Electrochemical detection of hydrogen peroxide release from alcohol-injured hepatocytes with miniature enzyme-based electrodes. Anal Chem 85:932-939

29. Attar A, Cubillana-Aguilera L, Naranjo-Rodriguez I, Hidalgo de Cisneros JLH, Santander JMP, Amine A (2015) Amperometric inhibition biosensors based on horseradish peroxidase and gold sononanoparticles immobilized onto different electrodes for cyanide measurements. Bioelectrochemistry 101:84-91

30. Chinnadayyala SR, Kakoti A, Santhosh M, Goswami P (2014) A novel amperometric alcohol biosensor developed in a 3rd generation bioelectrode platform using peroxidase coupled ferrocene activated alcohol oxidase as biorecognition system. Biosensor and Bioelectronics 55:120-126

31. Yang X, Chen X, Yang L, Yang W (2008) Direct electrochemistry and electrocatalysis of horseradish peroxidase in $\alpha$-zirconium phosphate nanosheet film. Bioelectrochemistry 74:90-95

32. Lei CX, Hu SQ, Gao N, Shen GL, Yu RQ (2004) An amperometric hydrogen peroxide biosensor based on immobilizing horseradish peroxidase to a nano-Au monolayer supported by sol-gel derived carbon ceramic electrode. Bioelectrochemistry 65:33-39

33. Zeng X, Li X, Liu X, Liu Y, Luo S, Kong B, Yang S, Wei W (2009) A third-generation hydrogen peroxide biosensor based on horseradish peroxidase immobilized on DNA functionalized carbon nanotubes. Biosens Bioelectron 25:806-900 